\title{
The Yersinia high-pathogenicity island and iron- uptake systems in clinical isolates of Escherichia coli
}

\author{
Ryszard Koczura and Adam Kaznowski
}

\begin{abstract}
Correspondence
Ryszard Koczura

koczma@amu.edu.pl
\end{abstract}

Received 7 February 2003

Accepted 2 April 2003

\author{
Department of Microbiology, Institute of Experimental Biology, Adam Mickiewicz University, 61-701 \\ Poznań, Poland
}

\begin{abstract}
The ability to acquire iron is crucial for bacteria during an infection. The capacity of 35 strains of Escherichia coli, isolated from clinical specimens, to use various strategies to obtain iron was analysed. The isolates employed several iron-uptake mechanisms, including production of enterobactin ( $86 \%$ ) and aerobactin (71\%). The majority of the isolates also excreted yersiniabactin, which is encoded by the Yersinia high-pathogenicity island (HPI). However, PCR analysis of the Yersinia HPI revealed diversity in its genetic organization. Use of human transferrin (91\%), lactoferrin (94\%), haemoglobin (80\%) and haemoglobin-haptoglobin complex (63\%) as the sole source of iron was common among $E$. coli isolates. Multiple iron-uptake systems may be of benefit to bacteria during an infection.
\end{abstract}

\section{INTRODUCTION}

Under conditions of iron stress, the vast majority of microorganisms induce high-affinity iron-transport systems to overcome the low availability of this essential element. In mammalian hosts, it is sequestered by iron-withholding proteins, such as transferrin in serum and cerebrospinal fluid or lactoferrin in cerebrospinal fluid, tears, milk and secretions of the respiratory, gastrointestinal and genital tracts. Most intracellular iron is bound by haem or stored in ferritin and haemosiderin (Weinberg, 1978; Payne, 1988). A typical high-affinity iron-uptake system consists of a lowmolecular-mass, $\mathrm{Fe}(\mathrm{III})$-specific ligand (termed a siderophore), its cognate membrane receptor and several proteins involved in transport of the ferri-siderophore across the cell wall (Griffiths et al., 1988; Martinez et al., 1990).

Escherichia coli has evolved several mechanisms to acquire iron, including the production of siderophores such as enterobactin and aerobactin. Some pathogenic strains produce cell-bound or secreted haemolysins that release haemoglobin from erythrocytes, making it available for haemoglobin proteases (Payne, 1988; Otto et al., 1998). Moreover, E. coli strains are capable of utilizing ferric dicitrate and iron that are bound to exogenous hydroxamate siderophores such as coprogen, rhodotorulic acid, ferrichrome and ferrioxamine B (Payne, 1988; Ratledge \& Dover, 2000).

Recent studies have revealed that some pathogenic E. coli isolates carry genes that encode yersiniabactin-mediated iron-uptake systems, clustered in a pathogenicity island

Abbreviations: CAS, chrome azurol S; HPI, high-pathogenicity island.
(Schubert et al., 1998; Bach et al., 2000). This pathogenicity island was originally found in Yersinia spp. isolates and was named a 'high-pathogenicity island' (HPI), as its presence is correlated with virulence. The Yersinia HPI displays features typical of a pathogenicity island: (i) it is a large fragment of the chromosome (36-43 kb, depending on the species); (ii) it carries genes essential for virulence; (iii) it is located in the vicinity of a tRNA gene; (iv) it contains insertion sequences and an integrase gene; and (v) it differs in $\mathrm{G}+\mathrm{C}$ content from the rest of the chromosome (Carniel, 2001).

So far, iron-acquisition studies in E. coli have not simultaneously investigated all mechanisms that can be used by strains of this species; therefore, the aim of the present work was to perform an extensive study of iron-uptake mechanisms used by clinical $E$. coli isolates, with focus on occurrence and genetic organization of the Yersinia HPI.

\section{METHODS}

Bacterial strains. Thirty-five E. coli strains were isolated from clinical specimens and identified using ID 32 GN strips in the ATB Expression system (bioMérieux). The strains were stored at $-75^{\circ} \mathrm{C}$ in heart infusion broth (Difco) that contained $50 \%(\mathrm{v} / \mathrm{v})$ glycerol. Origins of the strains are shown in Table 1.

Siderophore production. Bacterial ability to produce siderophores was checked initially by using chrome azurol S (CAS) assay solution (Schwyn \& Neilands, 1987). Production of enterobactin and aerobactin was detected by performing cross-feeding assays, which tested the ability of bacteria to promote growth of indicator strains grown under iron starvation. Enterobactin was detected by Salmonella typhimurium TA 2700 , which is defective in the biosynthesis of this siderophore but retains the receptor for the iron-enterobactin complex. Aerobactin production was detected by E. coli LG 1522, a strain that is deficient in the biosynthesis of this siderophore but has an intact receptor for ferri- 
Table 1. Haemolytic activity, siderophore production and presence of Yersinia HPI in clinical strains of E. coli

\begin{tabular}{|c|c|c|c|c|c|c|c|c|}
\hline \multirow[t]{2}{*}{ Strain } & \multirow[t]{2}{*}{ Source } & \multirow{2}{*}{$\begin{array}{c}\text { Haemolytic } \\
\text { activity }\end{array}$} & \multicolumn{3}{|c|}{ Siderophore production } & \multicolumn{3}{|c|}{ Size of PCR product (bp) } \\
\hline & & & Enterobactin & Aerobactin & Yersiniabactin & $\operatorname{irp1}$ & $\operatorname{irp2}$ & fyuA \\
\hline RK 3 & Urine & + & + & + & + & 240 & 280 & 780 \\
\hline RK 6 & Urine & + & + & + & + & - & 280 & 780 \\
\hline RK 13 & Urine & + & + & + & + & 240 & 280 & 750 \\
\hline RK 14 & Urine & - & + & + & + & 240 & 280 & 780 \\
\hline RK 15 & Urine & - & + & + & + & 240 & 280 & 780 \\
\hline RK 16 & Urine & - & + & + & + & - & - & 780 \\
\hline RK 17 & Urine & + & + & - & + & 240 & 280 & 780 \\
\hline RK 18 & Urine & + & + & - & + & 240 & 280 & 750 \\
\hline RK 20 & Urine & - & + & + & + & - & 280 & - \\
\hline RK 21 & Urine & + & + & + & + & 240 & 280 & 780 \\
\hline RK 22 & Urine & + & + & - & + & 240 & 280 & 750 \\
\hline RK 23 & Urine & + & + & - & + & 240 & 280 & 780 \\
\hline RK 24 & Urine & + & + & - & + & 240 & 280 & 780 \\
\hline RK 26 & Urine & - & + & - & + & - & 280 & 780 \\
\hline RK 27 & Urine & + & + & - & + & 240 & 280 & - \\
\hline RK 30 & Urine & - & + & - & - & - & - & - \\
\hline RK 36 & Urine & - & + & + & + & 240 & 280 & 780 \\
\hline RK 37 & Urine & - & + & + & + & - & 280 & 780 \\
\hline RK 4 & Blood & + & + & + & + & 240 & 280 & 780 \\
\hline RK 5 & Blood & - & + & - & - & - & - & - \\
\hline RK 7 & Blood & - & - & + & - & - & - & - \\
\hline RK 10 & Blood & - & - & + & - & - & - & - \\
\hline RK 12 & Blood & + & + & + & + & 240 & 280 & 750 \\
\hline RK 33 & Cervical canal & - & + & + & + & 240 & 280 & 780 \\
\hline RK 34 & Cervical canal & - & + & + & + & 240 & 280 & 780 \\
\hline RK 35 & Cervical canal & + & + & - & + & 240 & 280 & - \\
\hline RK 19 & Semen & + & + & + & + & 240 & 280 & 780 \\
\hline RK 28 & Semen & - & - & + & + & 240 & 280 & 780 \\
\hline RK 29 & Semen & + & + & + & + & - & 280 & 780 \\
\hline RK 11 & Conjunctiva & - & + & + & + & - & 280 & 780 \\
\hline RK 25 & Conjunctiva & - & - & + & + & - & - & 780 \\
\hline RK 9 & Wound & + & + & + & + & 240 & - & 780 \\
\hline RK 31 & Foreskin abscess & + & + & + & + & 240 & 280 & 780 \\
\hline RK 32 & Wound & - & + & + & + & 240 & 280 & 780 \\
\hline RK 8 & Cerebrospinal fluid & - & - & + & - & - & - & - \\
\hline
\end{tabular}

aerobactin (Reissbrodt \& Rabsch, 1988). Yersiniabactin detection was done with Yersinia enterocolitica 5030, a strain that uses exogenous yersiniabactin, and Y. enterocolitica 5092, a negative-control strain that neither produces nor utilizes yersiniabactin (Haag et al., 1993). Aureobacterium (formerly Arthrobacter) flavescens JG-9 was used for the detection of hydroxamate siderophores other than aerobactin (Reissbrodt \& Rabsch, 1988).

Haemolysin production assay. Aliquots $(10 \mu \mathrm{l})$ of bacterial suspension were transferred to holes ( $4 \mathrm{~mm}$ in diameter) punched in human blood agar plates. The plates were incubated for $24 \mathrm{~h}$ at $37^{\circ} \mathrm{C}$ and checked for haemolysis (Beecher \& Wong, 1994).

Utilization of human iron sources. Iron-deficient LB agar plates were prepared by adding ethylenediamine-di-(o-hydroxyphenylacetic acid)
(EDDHA) at a concentration sufficient to inhibit bacterial growth Overnight cultures were inoculated into molten Luria agar at a density of $10^{4}$ cells $\mathrm{ml}^{-1}$. Human haemoglobin, haemoglobin-haptoglobin complex, transferrin and lactoferrin (Sigma) were dialysed to remove contamination, incubated with $\mathrm{FeCl}_{3}$ to obtain $50 \%$ iron saturation and sterilized through a $0 \cdot 22 \mu \mathrm{m}$ filter (Staags \& Perry, 1991). Sterile paper discs were impregnated with these iron-binding proteins $(0.01 \mu \mathrm{mol}$ per disc) and placed onto the inoculated agar plates, which were then incubated for $48 \mathrm{~h}$ at $37^{\circ} \mathrm{C}$ and examined for zones of growth around the discs (Massad et al., 1991).

Detection of Yersinia HPI genes. HPI genes in clinical strains of $E$. coli were examined by using a PCR-based method. Bacterial DNA was isolated by using a QIAamp DNA Mini kit (Qiagen). Recombinant Taq polymerase and other PCR reagents were purchased from MBI 
Fermentas. Primers were synthesized by Genset Oligos; their sequences were published by Karch et al. (1999). PCR amplifications were performed in a $50 \mu \mathrm{l}$ volume with $5 \mu \mathrm{l} 10 \times$ PCR buffer with $\mathrm{NH}_{4}\left(\mathrm{SO}_{4}\right)_{2}, 0.6 \mu \mathrm{M}$ each primer, $200 \mu \mathrm{M}$ dNTP mix, $2.5 \mathrm{mM} \mathrm{MgCl}_{2}$, $2 \mathrm{U}$ Taq polymerase and $1 \mu \mathrm{g}$ genomic DNA. Amplification involved an initial denaturation step $\left(94^{\circ} \mathrm{C}, 5 \mathrm{~min}\right)$ followed by 30 cycles of denaturation $\left(94^{\circ} \mathrm{C}, 1 \mathrm{~min}\right)$, annealing (Karch et al., 1999) and extension $\left(72{ }^{\circ} \mathrm{C}, 1 \mathrm{~min}\right)$, with a final extension step $\left(72{ }^{\circ} \mathrm{C}, 8 \mathrm{~min}\right)$. PCR products were separated in 1.5 or $2 \%$ agarose gel. All experiments were performed in duplicate.

\section{RESULTS AND DISCUSSION}

\section{Production of enterobactin and aerobactin in clinical E. coli isolates}

CAS assay solution contains a dye that is blue when chelated with iron and turns to orange when a stronger chelator, such as a siderophore, removes the iron. All strains gave positive results in the assay, indicating production of iron-chelating compounds. The type of siderophore produced by the strains was determined in bioassays that examined the capability of each strain to induce the growth of indicator strains that are deficient in iron-uptake mechanisms. As the growth of the aerobactin indicator strain E. coli LG 1522 can also be stimulated by rhodotorulic acid (Reissbrodt \& Rabsch, 1988), we performed an additional bioassay with A. flavescens JG-9. All strains gave negative results in this test, which excluded the production of rhodotorulic acid.

Results of the cross-feeding assays are shown in Table 1 . Twenty of 35 E. coli isolates produced both enterobactin and aerobactin. Ten strains produced enterobactin only; aerobactin alone was secreted by five isolates. All uropathogenic E. coli isolates produced enterobactin, either alone or in combination with aerobactin.

\section{Haemolytic activity}

Seventeen (49\%) of $35 \mathrm{E}$. coli isolates showed $\beta$-haemolysis on human blood agar plates (Table 1). Haemolysin-producing strains were isolated from all sources except for conjunctiva and cerebrospinal fluid.

\section{Iron utilization studies}

A measure of the effectiveness of iron-acquisition systems is the capacity of bacterial strains to use iron-binding proteins as the sole iron source. We demonstrated the ability of E. coli strains to grow in the presence of human haemoglobin, haemoglobin-haptoglobin complex, transferrin and lactoferrin (Table 2). The ability to use transferrin and lactoferrin was prevalent (91 and $94 \%$ of strains, respectively). All haemolytic strains expressed growth in the presence of haemoglobin or the haemoglobin-haptoglobin complex. Overall, the proportions of isolates that were capable of using haemoglobin and haemoglobin-haptoglobin were 80 and $63 \%$, respectively. Utilization of haemoglobin, transferrin and lactoferrin has also been reported previously (Law et al., 1992; Dall'Agnol \& Martinez, 1999). E. coli was considered to be incapable of using the haemoglobin-haptoglobin
Table 2. Human iron sources utilized by $E$. coli isolates

\begin{tabular}{|c|c|c|c|c|}
\hline Strain & Haemoglobin & $\begin{array}{c}\text { Haemoglobin- } \\
\text { haptoglobin }\end{array}$ & Transferrin & Lactoferrin \\
\hline RK 3 & + & + & + & + \\
\hline RK 6 & + & + & + & + \\
\hline RK 13 & + & + & + & + \\
\hline RK 14 & + & + & + & + \\
\hline RK 15 & + & + & + & + \\
\hline RK 16 & - & - & + & + \\
\hline RK 17 & + & - & + & + \\
\hline RK 18 & + & - & + & + \\
\hline RK 20 & + & + & + & + \\
\hline RK 21 & + & + & + & + \\
\hline RK 22 & + & + & + & + \\
\hline RK 23 & + & + & + & + \\
\hline RK 24 & + & + & + & + \\
\hline RK 26 & - & - & + & + \\
\hline RK 27 & + & + & + & + \\
\hline RK 30 & - & - & + & + \\
\hline RK 36 & + & + & + & + \\
\hline RK 37 & + & + & + & + \\
\hline RK 4 & + & + & + & + \\
\hline RK 5 & + & + & + & - \\
\hline RK 7 & + & - & + & - \\
\hline RK 10 & - & - & + & + \\
\hline RK 12 & + & + & + & + \\
\hline RK 33 & - & - & + & + \\
\hline RK 34 & + & + & + & + \\
\hline RK 35 & + & + & + & + \\
\hline RK 19 & + & - & + & + \\
\hline RK 28 & + & - & + & + \\
\hline RK 29 & + & + & + & + \\
\hline RK 11 & - & - & + & + \\
\hline RK 25 & - & - & - & + \\
\hline RK 9 & + & + & + & + \\
\hline RK 31 & + & + & + & + \\
\hline RK 32 & + & - & + & - \\
\hline RK 8 & + & + & - & + \\
\hline
\end{tabular}

complex (Eaton et al., 1982, Helms et al., 1984); however, the uropathogenic strain CFT073, which possesses multiple iron-uptake systems, can use this complex (Torres et al., 2001).

\section{Screening for Yersinia HPI in E. coli strains}

The presence of the Yersinia HPI in genomes of E. coli isolates was detected by a PCR-based method that used primers specific for the Yersinia pestis genes irp1 and irp2 (yersiniabactin biosynthesis genes) and fyuA, also named $p s n$, which encodes the ferri-yersiniabactin receptor (Karch et al., 1999). All three HPI genes were present in $54 \%$ of $E$. coli strains. Overall, irp1 and irp2 were present in 63 and $77 \%$ of E. coli 
strains, respectively, and fyuA was detected in $77 \%$ of isolates. Five strains $(14 \%)$ were completely negative for the presence of Yersinia HPI genes (Table 1).

The sizes of PCR products generally tallied with expected values, although four isolates (RK 12, RK 13, RK 18 and RK 22) demonstrated a 750 bp product of fyuA that was shorter than the corresponding fragment in $Y$. pestis, which is $780 \mathrm{bp}$ long (Karch et al., 1999).

\section{HPI organization in E. coli isolates}

Nine E. coli strains were chosen for detailed analysis of the organization of the Yersinia HPI. The following genotypes were investigated: $\operatorname{irp} 1^{+} \operatorname{irp}^{+} f y u A^{+}$(isolates RK 17, RK 28 and RK 33), $\operatorname{irp1}^{+} \operatorname{irp}^{+}$fyuA-750 bp (RK 18 and RK 22), $i r p 1^{+} i r p 2^{+} f y u A^{-}$(RK 27 and RK 35) and $i r p 1^{-} i r p 2^{+} f y u A^{+}$ (RK 26 and RK 37). Strains were subjected to a set of PCR amplifications with primers complementary to single HPI genes as well as to regions that contained fragments of consecutive genes, which allowed us to determine the order of the genes. PCR products were obtained from the vast majority of investigated HPI regions and their sizes corresponded to $Y$. pestis homologues (Fig. 1). Analysis revealed diversity of the HPI in E. coli clinical isolates. Only one of nine scrutinized isolates, namely RK 33, possessed the whole set of Yersinia HPI genes. The other isolates failed in amplification of one or more of the following regions: $y b t S, y b t Q / y b t A$, irp1, $y b t T / f y u A$ and/or $f y u A$. In clinical E. coli isolates, the HPI was located in the vicinity of asnT (asparagine-specific tRNA gene). Amplification of the asnU/int and asnV/int regions gave no product. Insertion of the HPI in Yersinia pseudotuberculosis can occur in three tRNA loci: asnT, asnU and $a s n V$
(Buchrieser et al., 1998), whereas in E. coli it occurs mainly in the asnT gene (Schubert et al., 1998, 2000; Karch et al., 1999), although it is also possible in other locations (Clermont et al., 2001).

A shorter-than-expected PCR product of fyuA in some strains (Table 1) suggests partial deletion of the gene, which may affect the function of its product, the ferri-yersiniabactin receptor. A truncated fyuA gene has also been demonstrated in certain pathogenic E. coli isolates (Schubert et al., 1998). Deletions have also been shown for another HPI gene, int, which encodes an integrase (Karch et al., 1999; Gophna et al., 2001; Girardeau et al., 2003). As integrase genes can be involved in the mobility of pathogenicity islands (Hacker $e t$ al., 1997; Hensel et al., 1997), partial deletion of int may result in a non-functional integrase and stabilization of the HPI in the chromosome of E. coli isolates (Karch et al., 1999). A second possibility is that these strains have acquired the HPI by a non-integrase-based transfer event (Gophna et al., 2001). Amplification with primers designed for the IS100 sequence gave no product in strains RK 28 and RK 37. In other isolates, this PCR resulted in a 950 bp product, whereas the corresponding region in $Y$. pestis is $100 \mathrm{bp}$. Moreover, in some cases, we did not obtain a PCR product for a particular gene, despite obtaining amplicons of regions that link it with adjacent genes.

\section{Production of yersiniabactin}

The presence of Yersinia HPI genes in the chromosome of $E$. coli strains, detected by PCR amplification, does not confirm that the yersiniabactin-mediated iron-uptake system is functional. Expression of $f y u A$, irp1 and irp2 in E. coli has

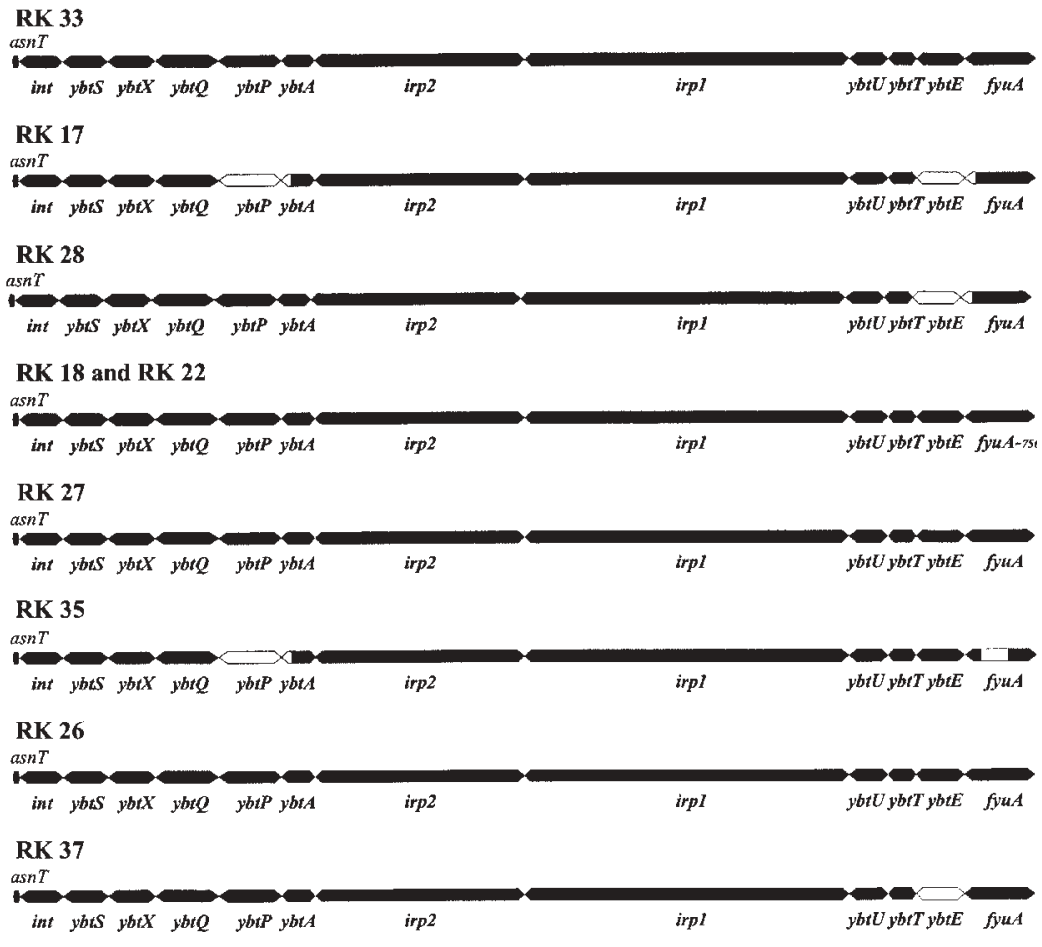

Fig. 1. Genetic organization of Yersinia HPI in nine clinical E. coli isolates. Genes are represented by black bars. White indicates chromosome fragments that are negative for PCR amplification. 
been demonstrated recently to be iron-regulated, which is typical of siderophore-mediated iron-acquisition systems in bacteria (Schubert et al., 1998; Karch et al., 1999; Bach et al., 2000). However, in some fyuA-positive isolates, the gene was not expressed (Karch et al., 1999). It has been demonstrated that supernatants of HPI-positive E. coli strains grown under iron-deficient conditions enhance expression of fyuA in $Y$. enterocolitica strain WA-CS $\operatorname{irp} 1:: \operatorname{Kan}^{\mathrm{R}}$ (pCJG3.3N), which harbours an $f y u A-g f p$ reporter gene fusion (Schubert et al., 2000). Provided that extracellular yersiniabactin positively regulates the expression of FyuA outer-membrane yersiniabactin receptor (Pelludat et al., 1998), this would indicate yersiniabactin production in $E$. coli.

In this study, all E. coli isolates were examined for production of yersiniabactin by using a bioassay with $Y$. enterocolitica 5030. Thirty of 35 isolates stimulated growth of the indicator strain in iron-poor medium (Table 1); therefore, we considered them to be HPI-positive. Moreover, none of them promoted growth of $Y$. enterocolitica 5092, indicating that they did indeed produce yersiniabactin. This suggests that the lack of PCR product for regions involved in yersiniabactin biosynthesis, i.e. $y b t S$, $i r p 1$ and $y b t T / f y u A$, in certain strains was probably caused by minor alterations of $E$. coli target sequences, which did not affect production of the siderophore.

Despite the lack of PCR product of some HPI marker genes in several isolates, we demonstrated yersiniabactin production in these strains. This suggests that detection of the HPI based on PCR amplification of one or even two genes alone may not be sufficient to show its presence in $E$. coli isolates. Thus, an appropriate bioassay or several PCRs should be carried out.

Our results showed that the vast majority of pathogenic isolates of E. coli possessed at least two iron-uptake systems. This feature may contribute to higher pathogenicity and facilitate colonization of the host organism. Whilst enterobactin- and aerobactin-mediated iron-uptake mechanisms have been studied thoroughly, the role of yersiniabactin in $E$. coli virulence is unclear. Both enterobactin and aerobactin have been shown to be prevalent in E. coli (Martinez et al., 1987; Reissbrodt \& Rabsch, 1988; Montgomerie et al., 1994). Production of haemolysins is less frequent (Johnson et al., 1988; Aumont et al., 1989). As enterobactin is bound by albumin and IgA in human serum (Moore \& Earhart, 1981), its function as a virulence factor is doubtful. The role of aerobactin in pathogenicity has been supported by epidemiological evidence (Valvano \& Crosa, 1984). Bearing in mind that enterobactin is inactivated in serum and that some isolates do not produce aerobactin, an additional siderophore (i.e. yersiniabactin) that has a higher affinity for ferric iron than aerobactin (Perry et al., 1999) would be of benefit to bacteria. Recently, Schubert et al. (2002), by using a mouse infection model, have shown that yersiniabactin contributes to virulence in extraintestinal pathogenic E. coli strains that lack both aerobactin and haemolysin. Multiple siderophore systems may function in different environments within the host, or at different stages during the course of an infection (Torres et al., 2001). The role of yersiniabactin in the virulence of $E$. coli needs further investigation. Moreover, demonstration of the coexistence of yersiniabactin- and aerobactin- or enterobactin-mediated iron-uptake systems in $E$. coli clinical isolates contributes to re-evaluation of the function of aerobactin and enterobactin in E. coli virulence, as yersiniabactin has not yet been taken into consideration when making such an evaluation.

\section{ACKNOWLEDGEMENTS}

We are grateful to Dr Rolf Reissbrodt, Professor Klaus Handtke and Professor Shelley M. Payne for kindly providing indicator strains. This work was partially supported by grant 6 P04C 10020 from the State Committee for Scientific Research to R. K.

\section{REFERENCES}

Aumont, P., Enard, C., Expert, D., Pieddeloup, C., Tancrede, C. \& Andremont, A. (1989). Production of haemolysin, aerobactin and enterobactin by strains of Escherichia coli causing bacteraemia in cancer patients, and their resistance to human serum. Res Microbiol 140, 21-26.

Bach, S., de Almeida, A. \& Carniel, E. (2000). The Yersinia highpathogenicity island is present in different members of the family Enterobacteriaceae. FEMS Microbiol Lett 183, 289-294.

Beecher, D. J. \& Wong, A. C. (1994). Identification of hemolysin BLproducing Bacillus cereus isolates by a discontinuous hemolytic pattern in blood agar. Appl Environ Microbiol 60, 1646-1651.

Buchrieser, C., Brosch, R., Bach, S., Guiyoule, A. \& Carniel, E. (1998). The high-pathogenicity island of Yersinia pseudotuberculosis can be inserted into any of the three chromosomal asn tRNA genes. Mol Microbiol 30, 965-978.

Carniel, E. (2001). The Yersinia high-pathogenicity island: an ironuptake island. Microbes Infect 3, 561-569.

Clermont, O., Bonacorsi, S. \& Bingen, E. (2001). The Yersinia highpathogenicity island is highly predominant in virulence-associated phylogenetic groups of Escherichia coli. FEMS Microbiol Lett 196, 153-157.

Dall'Agnol, M. \& Martinez, M. B. (1999). Uptake of iron from different compounds by enteroinvasive Escherichia coli. Rev Microbiol 30, 149-152.

Eaton, J. W., Brandt, P., Mahoney, J. R. \& Lee, J. T., Jr (1982). Haptoglobin: a natural bacteriostat. Science 215, 691-693.

Girardeau, J. P., Lalioui, L., Said, A. M. O., De Champs, C. \& Le Bouguénec, C. (2003). Extended virulence genotype of pathogenic Escherichia coli isolates carrying the $a f a-8$ operon: evidence of similarities between isolates from humans and animals with extraintestinal infections. J Clin Microbiol 41, 218-226.

Gophna, U., Oelschlaeger, T. A., Hacker, J. \& Ron, E. Z. (2001). Yersinia HPI in septicemic Escherichia coli strains isolated from diverse hosts. FEMS Microbiol Lett 196, 57-60.

Griffiths, E., Chart, H. \& Stevenson, P. (1988). High-affinity iron uptake systems and bacterial virulence. In Virulence Mechanisms of Bacterial Pathogens, pp. 121-137. Edited by J. A. Roth. Washington, DC: American Society for Microbiology.

Haag, H., Hantke, K., Drechsel, H., Stojiljkovic, I., Jung, G. \& Zahner, H. (1993). Purification of yersiniabactin: a siderophore and possible virulence factor of Yersinia enterocolitica. J Gen Microbiol 139, 2159-2165. 
Hacker, J., Blum-Oehler, G., Mühldorfer, I. \& Tschäpe, H. (1997). Pathogenicity islands of virulent bacteria: structure, function and impact on microbial evolution. Mol Microbiol 23, 1089-1097.

Helms, S. D., Oliver, J. D. \& Travis, J. C. (1984). Role of heme compounds and haptoglobin in Vibrio vulnificus pathogenicity. Infect Immun 45, 345-349.

Hensel, M., Shea, J. E., Bäumler, A. J., Gleeson, C., Blattner, F. \& Holden, D. W. (1997). Analysis of the boundaries of Salmonella pathogenicity island 2 and the corresponding chromosomal region of Escherichia coli K-12. J Bacteriol 179, 1105-1111.

Johnson, J. R., Moseley, S. L., Roberts, P. L. \& Stamm, W. E. (1988). Aerobactin and other virulence factor genes among strains of Escherichia coli causing urosepsis: association with patient charateristics. Infect Immun 56, 405-412.

Karch, H., Schubert, S., Zhang, D., Zhang, W., Schmidt, H., Ölschläger, T. \& Hacker, J. (1999). A genomic island, termed high-pathogenicity island, is present in certain non-O157 Shiga toxin-producing Escherichia coli clonal lineages. Infect Immun 67, 5994-6001.

Law, D., Wilkie, K. M., Freeman, R. \& Gould, F. K. (1992). The iron uptake mechanisms of enteropathogenic Escherichia coli: the use of haem and haemoglobin during growth in an iron-limited environment. J Med Microbiol 37, 15-21.

Martinez, J. L., Cercenado, E., Baquero, F., Perez-Diaz, J. C. \& DelgadoIribarren, A. (1987). Incidence of aerobactin production in Gramnegative hospital isolates. FEMS Microbiol Lett 43, 351-353.

Martinez, J. L., Delgado-Iribarren, A. \& Baquero, F. (1990). Mechanisms of iron acquisition and bacterial virulence. FEMS Microbiol Rev 6, $45-56$.

Massad, G., Arceneaux, J. E. L. \& Byers, B. R. (1991). Acquisition of iron from host sources by mesophilic Aeromonas species. J Gen Microbiol 137, 237-241.

Montgomerie, J. Z., Bindereif, A., Neilands, J. B., Kalmanson, G. M. \& Guze, L. B. (1984). Association of hydroxamate siderophore (aerobactin) with Escherichia coli isolated from patients with bacteremia. Infect Immun 46, 835-838.

Moore, D. G. \& Earhart, C. F. (1981). Specific inhibition of Escherichia coli ferrienterochelin uptake by a normal human serum immunoglobin. Infect Immun 31, 631-635.

Otto, B. R., van Dooren, S. J. M., Nuijens, J. H., Luirink, J. \& Oudega, B. (1998). Characterization of a hemoglobin protease secreted by the pathogenic Escherichia coli strain EB1. J Exp Med 188, 1091-1103.
Payne, S. M. (1988). Iron and virulence in the family Enterobacteriaceae. Crit Rev Microbiol 16, 81-111.

Pelludat, C., Rakin, A., Jacobi, C. A., Schubert, S. \& Heesemann, J. (1998). The yersiniabactin biosynthetic gene cluster of Yersinia enterocolitica: organization and siderophore-dependent regulation. J Bacteriol 180, 538-546.

Perry, R. D., Balbo, P. B., Jones, H. A., Fetherston, J. D. \& DeMoll, E. (1999). Yersiniabactin from Yersinia pestis: biochemical characterization of the siderophore and its role in iron transport and regulation. Microbiology 145, 1181-1190.

Ratledge, C. \& Dover, L. G. (2000). Iron metabolism in pathogenic bacteria. Annu Rev Microbiol 54, 881-941.

Reissbrodt, R. \& Rabsch, W. (1988). Further differentiation of Enterobacteriaceae by means of siderophore-pattern analysis. Zentbl Bakteriol Mikrobiol Hyg A 268, 306-317.

Schubert, S., Rakin, A., Karch, H., Carniel, E. \& Heeseman, J. (1998). Prevalence of the "high-pathogenicity island" of Yersinia species among Escherichia coli strains that are pathogenic to humans. Infect Immun 66, 480-485.

Schubert, S., Cuenca, S., Fischer, D. \& Heesemann, J. (2000). Highpathogenicity island of Yersinia pestis in Enterobacteriaceae isolated from blood cultures and urine samples: prevalence and functional expression. J Infect Dis 182, 1268-1271.

Schubert, S., Picard, B., Gouriou, S., Heesemann, J. \& Denamur, E. (2002). Yersinia high-pathogenicity island contributes to virulence in Escherichia coli causing extraintestinal infections. Infect Immun $\mathbf{7 0}$, 5335-5337.

Schwyn, B. \& Neilands, J. B. (1987). Universal chemical assay for the detection and determination of siderophores. Anal Biochem 160, 47-56.

Staggs, T. M. \& Perry, R. D. (1991). Identification and cloning of a fur regulatory gene in Yersinia pestis. J Bacteriol 173, 417-425.

Torres, A. G., Redford, P., Welch, R. A. \& Payne, S. M. (2001). TonBdependent systems of uropathogenic Escherichia coli: aerobactin and heme transport and TonB are required for virulence in the mouse. Infect Immun 69, 6179-6185.

Valvano, M. A. \& Crosa, J. H. (1984). Aerobactin iron transport genes commonly encoded by certain ColV plasmids occur in the chromosome of a human invasive strain of Escherichia coli K1. Infect Immun 46, 159-167.

Weinberg, E. D. (1978). Iron and infection. Microbiol Rev 42, 45-66. 